\title{
$\mathrm{PH} 9 \mathbf{9 7}$
}

\section{Vernacularmente: patrimonio cultural y retos de sociedad}

El municipio de Valverde de Burguillos (Badajoz) acoge la experiencia piloto de la iniciativa Vernacularmente, surgida en 2017, que persigue la verdadera aplicabilidad social de los resultados de investigaciones, proyectos o acciones desarrolladas en el marco académico. Desde un concepto amplio del patrimonio, el equipo trabaja en la identificación de valores patrimoniales, el rescate de la esencia del patrimonio, la detección de potencialidades y la puesta en valor los recursos endógenos de entornos habitados con baja densidad y vulnerables a la despoblación, para que los agentes implicados en el desarrollo local trabajen conectados y cooperen mediante una red colaborativa.

Victoria Domínguez Ruiz | Instituto Universitario de Ciencias de la Construcción, Universidad de Sevilla Julia Rey Pérez | Dpto. de Historia, Teoría y Composición Arquitectónica, Universidad de Sevilla

URL de la contribución <http://www.iaph.es/revistaph/index.php/revistaph/article/view/4375>

Desde el año 2015 la Universidad de Sevilla ${ }^{1}$ colabora con el Ayuntamiento de Valverde de Burguillos y la Mancomunidad en temas relacionados con la agroecología, los sistemas agrarios, las variedades locales y las plantas silvestres. Posteriormente, Vernacularmente ${ }^{2}$ se sumó al proyecto, dedicándose al patrimonio arquitectónico, cultural, al concepto de turismo sostenible, bases de datos y tecnologías web.

Estas líneas de trabajo, orientadas al emprendimiento, la innovación, la tecnología, la sostenibilidad y la solidaridad, activan un modo de pensar vernáculo que, sin renunciar a las comodidades del mundo global, tenga en cuenta soluciones de origen que hicieron sostenibles determinadas formas de vida hasta hoy. En ese sentido, Vernacularmente ha organizado la serie de Talleres de iniciativas vernáculas, donde se trazan un conjunto de ideas que abarcan y fomentan el patrimonio vernáculo, tanto cultural como natural, como motor potencial de desarrollo local. El primer taller (diciembre de 2017) fomentó un marco de colaboración interdisciplinar entre estudiantes, investigadores, instituciones, asociaciones y emprendedores, tratando de enunciar sinergias para el desarrollo económico, tecnológico y social en el ámbito urbano-rural-vernáculo de Valverde. Se detectaron nuevas áreas de oportunidad susteptibles de desarrollo futuros proyectos. La metodología empleada implicó a los participantes: dinámicas grupales de aproximación, diagnóstico y análisis de Debilidades, Amenazas, Fortalezas y Oportunidades (DAFO), y un planteamiento práctico dieron lugar a propuestas muy creativas.

En abril de 2018 se realizó el segundo taller, con participación ciudadana, que consiguió identificar nuevos valores patrimoniales de Valverde de Burguillos no tenidos en cuenta por la Administración encargada de la conservación y la planificación. A través de fichas tematizadas con los 5 sentidos (vista, olor, gusto, tacto y oído) se recogían justificadamente aquellos elementos del patrimonio cultural que singularizan el municipio, las anomalías y sugerencias para mejorarlos. El resultado destacó el paisaje en general, donde toman protagonismo la naturaleza y el entorno, así como la cuestión de las visiones desde el pueblo hacia el territorio y la componente urbana. Cuestiones inmateriales, como la gastronomía, los sonidos de los pájaros, el olor a campo o tierra mojada o la personalidad de los valverdeños fueron resaltados, dando una idea de las singularidades del patrimonio de este lugar, hasta ahora no reconocido en los instrumentos de gestión. El equipo técnico que participa aporta un conocimiento especializado en arquitectura, patrimonio cultural, economía, energía e informática. Desde su experiencia docente, investigadora y profesional, se han desarrollado proyectos de ámbito nacional e internacional en contacto con otros centros de investigación, con la ciudadanía, con profesiones ligadas al desarrollo local y la difusión cultural, corporaciones y gobiernos de entornos de baja densidad de población. 
La idea motriz surge desde un enfoque doble. Por un lado, para combatir el pronóstico desolador de la ONU: para 2030 dos tercios de la población mundial vivirá en ciudades; duplicándose la población urbana en países en desarrollo y triplicándose el área cubierta por las ciudades. Por otro, atiende al problema de la despoblación y el éxodo rural, que es considerado por el Parlamento Europeo como prioritario.

Aunque existen otras propuestas que abordan el desarrollo local en zonas de baja densidad de población, ésta, naciendo en el ámbito académico, se diferencia por considerar el patrimonio vernáculo como un verdadero motor de desarrollo en línea con las necesidades del mundo global (rehabilitación arquitectónica, energética, de infraestructuras, accesibilidad y usabilidad). Supone una contribución diferenciadora la generación y aplicación del conocimiento científico a través del vínculo con la universidad. La creación de modelos digitales de información ${ }^{3}$ reactiva el patrimonio vernáculo y mejora el conocimiento integrado, pudiendo contribuir a ser motor e hilo conductor de acciones encaminadas a la repoblación de antiguas localidades, creación de puestos de trabajo, nacimiento de nuevas iniciativas económicas, recuperación de artesanías y antiguos oficios, creación de nuevos espacios culturales o de investigación, etc. En la experiencia piloto en el municipio de Valverde de Burguillos (en desarrollo) se ha colaborado en la convergencia entre la administración local, provincial y regional, una ciudadanía activa y la universidad para estudiar la viabilidad de un desarrollo local proyectado más allá de sus fronteras. En concreto existe una alineación a las estrategias de la asociación Activa Valverde, que ya realizó un análisis del problema y enunció un diagnóstico preocupante: problemas de acceso a la vivienda, falta de empleo que retenga a los jóvenes y atraiga a nuevos habitantes, temor por la pérdida de servicios y desencanto por la insuficiente implicación ciudadana. Por todo ello se plantea una contribución en la construcción de un nuevo concepto de ruralidad, que asuma de manera sostenible una alternativa válida mediante un proyecto integrado, colaborativo e interdisciplinar.

En la actualidad se está realizando un Sistema de Información Patrimonial con GIS para el contraste de la información derivada por los tres actores: la recopilada de la ciudadanía, la identificada en los trabajos académicos y de investigación por parte de la Universidad y los elementos que considera la Administración en sus documentos oficiales. En un próximo encuentro entre actores se pondrá en común toda la información generada. El objetivo será entonces definir, entre todos, los valores patrimoniales, criterios, estrategias y líneas de acción para implementar en Valverde de Burguillos. Se espera que los beneficios tanto al entorno rural como al urbano, en materia de dinamización cultural, turismo y desarrollo sostenibles, aprendizaje, conocimiento y formación puedan generar desarrollo económico en pequeñas poblaciones. Además, se afronta un reto social de gran alcance: el freno a la despoblación, consiguiendo la recuperación de valores tradicionales, situando el patrimonio como sello identitario, en definitiva, contribuyendo a aumentar la calidad de vida no sólo para sus habitantes, sino para los nuevos pobladores.

\section{NOTAS}

1. Se realizan estudios precedentes de referencia de la mano del profesor Rufino Acosta Naranjo, del Dpto. de Antropología Social de la U. de Sevilla, así como estudiantes realizan sus Tesis de fin de Máster (TFM) y Trabajo de Fin de Grado (TFG) o desarrollan prácticas curriculares de master en Valverde.

2. Con profesores y estudiantes de la Escuela Técnica Superior de la Arquitectura y Escuela Técnica Superior de Ingeniería Informática de U. De Sevilla, dirigiendo TFGs y TFMs,

3. Este tema es abordado desde la Acción A1.1 (grupo. us.es/tutsosmodhum/?page_id=420) del proyecto I+D+i del Plan Nacional con referencia HAR2016-78113-R que explora modelos digitales de información aplicándolos a la gestión sostenible de la tutela patrimonial, fundamentalmente basados en BIM (Building Information Modelling) y SIG (Sistemas de Información Geográfica). 